\title{
El sistema multilateral de comercio y la región ${ }^{*}$
}

\author{
Dorotea López G \\ Felipe Muñoz N.
}

Resumen

El futuro del sistema multilateral de comercio es actualmente tema de preocupación para las definiciones de política de los paises. La suspensión de las negociaciones cle la Ronda cle Doha parece haber puesto en jaque a! sistema, a pesar n que aún es ciemasiado pronto para llegar a una conclusión definitiva. Este documento revisa sus principales causas $y$ los riesgos que el sistema enfrenta ante una posible extensión de ćsta o un fraciso definitivo de la Ronda. Asimismo, se identifican las posiciones divergentes y coincidentes que los paises de America Latina y el Caribe han tenido hasta alora, y los distintos blocteses negociaclores que han formado bajo el enfoque de "geometría variablen. A pesar del heterogéneo mosaico político de la región existe un significativo número de temas que permitirian definir tulil postura común en ciertos aspectos de la negociación, como ser agricultura, NANA, servicios y facilitación del comercio.

\section{Abstract}

The multilateral trading system's future is a major concern for individual countries policy definition. The suspension of the Doha Round negotiations seems to be jeopardizing the system, although it is still too early to reach any definitive conclusion. This document reviews the main difficulties underlying the suspension of negotiations and the eventual consequences for the system of a more sustained impasse or the outright failure of the process. Moreover, the paper underlines the negotiating positions of the Latin American and Caribbean countries, identifying differences and commonalities within the region as well as the various negotiating blocks established according to the "variable geometry" approach. Notwithstanding the apparently mixed political mosaic of the region there is a significant number of areas whicla could contribute to defining a common position vis à vis such elenents of negotiations as agriculture, NAMA, services and trade facilitation.

- Agradecemos el valioso a porte del Profesor Prnncisco Pricto, Dircetor del Centro de Estudios de Política Comercial, del Instituto de Estudios Internacionales, así como los comentarios del Prof. Alrocar Simenfosina. 


\section{INTRODUCCIÓN}

En las últimas décadas el comercio internacional ha crecido de manera exponencial. Desde la Segunda Guerra Mundial las barreras comerciales se han regulado por el Acuerdo General sobre Aranceles y Comercio (GATT, por su sigla en inglés), la Organización Mundial de Comercio (OMC), y los acuerdos preferenciales. La tendencia general del comercio mundial apunta hacia la liberalización, y en este marco se han desarrollado las rondas multilaterales de negociación comercial, primero bajo el GATT $y$, desde el Acuerdo de Marrakech, bajo la OMC. Al mismo tiempo, la mayoría de los países han declarado que la liberalización comercial es un objetivo prioritario de su política $y$ actualmente las exportaciones han duplicado el producto mundial, indicando una creciente profundización de la integración económica global.

A pesar de lo anterior, a mediados del 2006 se suspendieron las negociaciones de la Ronda de Doha para el Desarrollo. Las profundas diferencias existentes entre los miembros de la OMC no dieron espacio a la continuación de las negociaciones. En esa oportunidad, el Director General de la organización declaró: «.... en esta asamblea no hay vencedores ni vencidos. Hoy, sólo hay vencidos." ${ }^{1}$ Asimismo, declaró que los que más pierden son los más pobres $y$, por lo tanto, habría que buscar un mecanismo para mantener a flote las negociaciones..

La interrupción de las negociaciones ha generado profunda prcocupación por el futuro de! sistema multilateral del comercio, y en particular por su impacto en los países en desarrollo. Sin embargo, en cierta medida se ha sobredimensionado el estado de alarma. Debemos recordar lo que duraron otras Rondas (por ejemplo, la Ronda Uruguay se desarrolló durante nueve años), así como las particularidades de la Ronda de Doha que estableció plazos que han ejercido excesiva presión en el sistema y son poco cercanos a la realidad, sus ambiciosas metas y la inclusión de un tema tan polémico como el desarroilo. En este escenario lo sorprendente hubiese sido que las negociaciones llegaran a su fin sin problemas.

Hasta ahora los principales protagonistas se han preocupado más de trasladar a otros la responsabilidad del fracaso de julio ${ }^{2}$-especialmente dentro del triángulo formado por los Estados Unidos, la Unión Europea y el Grupo de los 20-. Asimismo, han destacado su disposición a seguir negociando si los demás países presentan ofertas más sustanciales que permitan preservar el grado de ambición a que se aspira en esta Ronda. En vista de ello, se han iniciado reuniones informales entre algunos Miembros, y se han implementado al-

- Lamy, Pascal, Director General de la Organización Mundial del Comercio, "Discurso pronunciado por el DG", <http://wwwwto.org>, 24 de julio de 2006.

2 Peña, Fếlix, "Parálisis en la Rueda Doha y tendencias al bilateralismo", <http:/l www.felixpena.coms, agosto 2006. 
gunas estrategias dentro de la llamada "suave reanudación».

Los países desarrollados han desempeñado un rol particularmente importante tanto en la negociación como en la suspensión de la Ronda. A pesar de las diferencias entre las economías latinoamericanas, el futuro del sistema multilateral de comercio es de fundamental relevancia para su definición de la política comercial y de desarrollo.

La política comercial se ha convertido en uno de los instrumentos privilegiados para llevar adelante la transformación económica, institucional y normativa ${ }^{3}$. En la actualidad ella abarca un conjunto muy amplio de materias que van mucho más allá del concepto más tradicional, que se ha limitado a examinar el manejo de las variables que inciden directamente en el comercio de bienes. Los países de la región aún enfrentan importantes barreras arancelarias y no arancelarias para acceder a los grandes mercados, cuya eliminación podría tener un significativo impacto positivo en sus economías. Más aún, Prieto ${ }^{4}$ ha afirmado que demorar los esfuerzos en pro de una mayor integración a la economía de servicios en los países de la región puede tener serias consecuencias para la capacidad de avanzar hacia un desarrollo económico sostenible.

Sumado a lo anterior, el fracaso de las negociaciones iniciadas en Qatar el año 2001 puede hacer reflotar el riesgo de que los países vuelvan a adoptar y aplicar políticas de carácter proteccionista. "La alternativa es un repliegue de los países hacia viejas y desgastadas prácticas de cerrarse en sí mismos, redistribuir pobreza y encontrar allí la perfecta excusa para el fracasado camino de los populismos de siempre» ${ }^{5}$.

El año $2007^{6}$, en que se celebra el sexagésimo aniversario de la creación del GATT, antecesor de la OMC, serä determinante para el futuro del sistema multilateral de comercio. No necesariamente para concluir la Ronda, pero sí para renovar la voluntad política y las actividades formales de negociación en el seno de la OMC, ya que si continúa la suspensión puede producir un congelamiento del sistema y la Organización puede tornarse irrelevante y conducir a un deterioro gradual de sus funciones.

El presente documento examina la suspensión de las negociaciones y sus posibles consecuencias en el sistema multilateral de comercio, así como los efectos para los países en desarrollo en

3 Prieto, Francisco, "Discurso inaugural del Centro de Estudios de Política Comercial", Estudios Internacionales, $\mathrm{N}^{\mathbf{0}} 153$, 2006, p.147.

4 Prieto, Francisco, "Fomento y diversiffcación de las exportaciones de servicios», Comercio Exterior, CEPAL, 2004.

$s$ Foxley, Alejandro, Ministro de Relaciones Exteriores de Chile, "Intervención en la Reunión Ministerial de la OMC", Ginebra, Suiza, 30 de junio de 2006.

6 Lamy, Pascal, «Doha's final deadline, The world in 2007", The Economist, 21st special edition, 2007. 
particular de América Latina. Asimismo, revisa la posición adoptada por estos y plantea la necesidad de que la región dé muestras de coherencia, consistencia y consenso a largo plazo para introducir medidas que mejoren su competitividad. En el diseño de sus estrategias, los países de la región deben considerar sus diferencias e intentar estrecharlas a fin de que la política comercial y de desarrollo que les permita alcanzar sus objetivos a nivel multilateral y aprovechar los beneficios de la liberalización comercial.

En la primera sección se revisan las razones que llevaron a suspender las negociaciones en el marco de la OMC como consecuencia de acontecimientos anteriores a la suspensión de la Ronda de Doha, tanto relacionados con factores inherentes a los temas de negociación como a los aspectos políticos que han influido en ella. Desde distintos puntos de vista, la segunda sección estudia las consecuencias de un posible fracaso de las negociaciones. La tercera sección hace particular hincapié en los efectos en la región y bosqueja las definiciones y prioridades establecidas por cada uno de los países frente a este proceso de negociación, para llegar a algunas consideraciones finales.

\section{LAS CAUSAS DE LA SUSPENSIÓN DE LAS NEGOCIACIONES}

La interrupción de las negociaciones implicó, «en términos prácticos, que ahora se deberían suspender los trabajos en todos los grupos de negociación, y lo mismo cabe decir de los plazos que los distintos grupos tenían ante sí» ${ }^{7}$. Como se mencionó, 2007 será un año fundamental para el sistema multilateral de comercio y para revitalizar la Ronda de Doha.

En la presente sección se examinan las principales causas de la interrupción que, de manera arbitraria, hemos clasificado en aspectos técnicos inherentes a la negociación, que se revisan en la primera parte, y aspectos de carácter político y estratégico, sin perder de vista que ambos factores se vinculan estrechamente y suele ser difícil delimitarlos.

Las aspiraciones de la actual Ronda de negociaciones son mucho mayores que las de las rondas anteriores en el sentido de que los compromisos que deben asumir los países Miembros de la $\mathrm{OMC}$ son muy superiores. En efecto aumentan no solo el número y dificultad de los temas sino también el de los actores involucrados. «En esta Ronda, los Miembros han adoptado un nivel de ambición equivalente al triple o incluso al cuádruplo del fijado en la Ronda Uruguay. En consecuencia, han decidido sustituir la "reducciones medias"

7 Lamy, Pascal, Director General de la Organización Mundial del Comercio, «Discurso pronunciado por el DG», 24 de julio de 2006. 
por un método que permita recortar sustancialmente los aranceles respecto de todos y cada uno de los productos agropecuarios. Además, han acordado que los aranceles más elevados sean objeto de mayores reducciones. Por ello, al contrario de la Ronda Uruguay, los países ya no podrán escudarse en sus aranceles más altos»" ${ }^{8}$.

La suspensión se produjo tras una sucesión de intentos fallidos por llegar a un acuerdo en las modalidades de negociación, indefinición que ha repercutido en el desconocimiento de los niveles de compromiso que implican para cada país. Por esta razón, los Miembros no han estado dispuestos a mostrar abiertamente su verdadera posición $y$ aparentemente perciben que los «espacios de política” que tendrían después de asumir los compromisos son menores que en Rondas anteriores.

Las negociaciones agrícolas han sido el tema clave de la suspensión, generado en parte por las diferencias que se manifiestan al interior del G-6 ${ }^{9}$. En materia agricola, los principales responsables de que existan distorsiones son los países desarrollados, que son los que destinan una enorme cantidad de recursos a apoyar a la agricultura. En cam- bio, para los países en desarrollo el nivel de empleo y las exportaciones de este sector continúan siendo muy relevantes para su economía, ya que alrededor de $70 \%$ de los pobres de estos países vive en zonas rurales. Por esta razón la eliminación de las barreras comerciales en la agricultura es de suma importancia para el desarrollo ${ }^{10}$.

No obstante que el comercio de productos agropecuarios reviste gran importancia para los países en desarrollo $y$ es de especial sensibilidad para los desarrollados, se ha atribuido excesiva relevancia a los aspectos agrícolas en el comercio internacional. En efecto, la agricultura representa solamente el $7 \%$ del comercio mundial, mientras las manufacturas y los servicios contribuyen el $61 \%$ y el $20 \%$ respectivamente ${ }^{11}$.

En materia agricola, los tres pilares de la negociación que se han definido son: la competencia de las exportaciones, la ayuda interna y el acceso a los mercados ${ }^{12}$.

El primer pilar abarca temas tales como las subvenciones a la exportación, los créditos a la exportación, la ayuda alimentaría y las empresas del Estado. Entre ellos, las primeras han sido el tema clave y pese a los avances logra-

8 Lamy, Pascal, "Discurso con ocasión del $20^{\circ}$ Aniversario del Grupo de Cairns", 20 de septiembre de 2006.

9 Australia, Brasil, Estados Unidos, India, Japón, Unión Europea.

10 Banco Mundial, "El comercio, la Ronda de Doha y la reducción de la pobreza», <http:// www.bancomundial.org>, agosto 2006.

$"$ Hufbauer, Clyde Gary. "The Causes and Costs of Failure», Asamblea General de las Naciones Unidas, 30 octubre, 2006.

12 Para profundizar en el tema se sugiere revisar Péréz del Castillo, "La agricultura de las Américas frente a la agenda de Doha para el Desarrollon, Instituto Interamericano de Cooperación para la Agricultura, noviembre de 2005. 
dos por el compromiso de la Unión Europea de eliminarlos unilateralmente, aún hay demandas pendientes al respecto. Es importante que este compromiso adquiera mayores garantías jurídicas que permitan asegurar que no se retire de forma unilateral.

El segundo pilar, que es el apoyo intemo, ha debido enfrentar la decisión de los Estados Unidos de ser inflexibles en esta materia $y$ de que ofreció una reducción insuficiente para la mayoría, argumentando que desconocía las posiciones respecto del acceso a los mercados de productos no agrícolas. «Lo que han ofrecido (EUA) implica cambios en su política agrícola, pero no hay un corte efectivo en materia de gasto en la agricultura de su país ${ }^{13}$ ". Aún hay trabajo por realizar para lograr que además de reducirse los apoyos ellos sean realmente no distorsionantes.

Finalmente, en lo que se refiere al acceso a los mercados agrícolas, Estados Unidos exige compromisos de reducción más ambiciosos que la UE y el G-20, cuya posición ha sido más conservadora y además ha ejercido presión para que Japón y la India reduzcan sus aranceles. Por su parte, la Unión Europea no ha aclarado su posición respecto de los productos especiales, que según algunos estudios podría representar una política extremadamente proteccionista. Aun así, lo conseguido hasta julio constituía un avance enorme en comparación con los resultados de la
Ronda Uruguay.

El tema del acceso a mercados de los productos no agrícolas (NAMA por su sigla en inglếs ${ }^{14}$ ) está detenido hasta que haya avances en materia agrícola. Hay que recordar que esta negociación tiene el formato de un todo único, o "single undertaking». A pesar de esto, se han alcanzado algunos consensos importantes, tales como la aplicación de una fórmula suiza, lo que sitúa el debate en las mesas de negociación en torno a los coeficientes que deben aplicarse a cada uno de los Miembros en relación con esta formula, y a cómo introducir en dichos coeficientes las flexibilidades que pide el mundo en desarrollo. Todavía se negocian los niveles de base que deben tener los productos cuyos aranceles aún no se han consolidado, entre otros aspectos.

No obstante que las barreras arancelarias son cada día un problema menor, aún hay problemas pendientes en lo que toca a la liberalización comercial. En materia de NAMA, los países desarrollados han definido metas ambiciosas, mientras que algunas economías en desarrollo no están dispuestas a abrir sus mercados de manufacturas y los países menos adelantados piden acceso sin siquiera estar dispuestos a abrir los suyos. En este tema, Brasil y la India contribuyeron de manera importante a la suspensión de las negociaciones al mostrarse inflexibles ya que se negaron categóricamente a re-

13 Jara, Alejandro, "Entrevista», Diario El Financiero, 26 de julio del 2006.

14 Non Agricultural Market Access. 
ducir los aranceles de los bienes industriales ${ }^{15}$.

En el campo del comercio de servicios se han registrado avances, como ser la decisión de dar mayor importancia a las negociaciones de carácter plurila-teral. Sin embargo, hasta ahora ninguna de las ofertas representa nuevas oportunidades de negocios para los Miembros. Para Aaditya Mattoo, las negociaciones han caído en una especie de trampa de bajo nivel: se ofrece poco y se espera menos ${ }^{16}$.

La facilitación del comercio, cuya finalidad es reducir los costos de transacción facilitando los flujos y las formalidades aduaneras, es fundamenta! para la región. Al respecto, hay consenso sobre su relevancia, pero el tema depende de los avances en agricultura.

El trato especial $y$ diferenciado es la pieza clave en el marco de una Ronda para el Desarrollo en la que incluso al interior de los propios países en desarrollo hay visiones múltiples. Algunos países se han marginado a la espera de lograr equilibrio en las concesiones, mientras que otros han hecho propuestas más osadas, como su eliminación en favor de otras concesiones y apoyos. Se ha llegado a interpretar el tema como si se tratara de no necesidad de reci- procidad, al menos por los países menos adelantados (PMA), lo que se ha llamado la "Ronda gratis». "Algunos estaban más interesados en las excepciones que en el acceso a los mercados» ${ }^{17}$.

Como se dijo, en la suspensión hay otras consideraciones de tipo estratégico y actualmente político. El mapa de los grandes actores confrontando el sistema para el éxito de las negociaciones es diferente y evidentemente más complejo que el existente en la Ronda Uruguay. En sus inicios el GATT tenía una relativa homogeneidad, que dista mucho de la actual conformación de la OMC.

Las negociaciones se desarrollaron en un contexto de constante cambio. Los países Miembros, en particular los que tienen mayor poder negociador y de definición enfrentaron diferentes situaciones que influyeron en las negociaciones y provocaron su suspensión. Para Alejandro Jara ${ }^{18}$, la falla en las negociaciones se debe principalmente a las limitaciones que imponen en sus propias políticas internas los distintos gobiernos.

Por un lado, la Unión Europea se encontraba en proceso de reforma para modificar radicalmente la forma en que apoyaba a su sector agrario mediante

Saborío, Ronald. "Situación actual de la Ronda de Doha de Negociaciones Comerciales Multilaterales", palabras del Embajador, representante permanente de Costa Rica ante la OMC, San José, 11 de agosto de 2006.

Mattoo, Aditya, "Services in a Development Round: Proposals for Overcoming Inertia", en "Trade, Doha and Development a Window to the Issues", Newfarmer Richard (ed.), Banco Mundial, 2005.

17 Saborio, Ronald, op cit.

18 Jara, Alejandro, "Entrevista», Diario el Financiero, 26 julio 2006. 
la Política Agrícola Común ${ }^{19}$, además de que centraba la atención en enfrentar las presiones a que daba lugar su ampliación. Sin entrar en un análisis de la situación de cada uno de los países, hay otros factores que influyen de manera importante, como la definición de la política comercial y los procesos eleccionarios y migratorios.

La situación política al interior de los Estados Unidos y sus repercusiones en las negociaciones de la Ronda de Doha ha sido tema de constante especulación. Por una parte, la guerra de Irak y su aún no del todo dimensionado efecto sobre la economía y la política, además de los déficit tanto en la cuenta de capital como en la cuenta corriente. Por la otra, el límite para el logro de un acuerdo sería junio de 2007 debido a que en esa fecha vence la Trade Promotion Authority (TPA). El reciente triunfo de los demócratas en las elecciones parlamentarias estadounidenses ha traído consigo un profundo temor acerca de la posibilidad de su prórroga y de reformular el Farm-Bill.

Las coaliciones de los países en desarrollo han desempeñado un rol importante en la suspensión de las negociaciones. El mundo en desarrollo está mucho más fragmentado, y en algunas materias se ha tropezado con dificultades para llegar a consenso. Además, los países en desarrollo han planteado una serie de expectativas, que suelen ir más allá del libre comercio y que podrían plantear un problema de foro.

Nuevos protagonistas del escenario comercial como China y la India provocan en otros el temor de tener que enfrentar un proceso de desindustrialización y desempleo frente a la apertura de sus mercados, y una especie de impasse en espera de la evolución de economías como la china.

Los países miembros de reciente adhesión consideran que esta Ronda impone exigencias superiores a su capacidad, ya que aún se encuentran en proceso de introducir las reformas necesarias y de solventar los costos de su ingreso a la OMC.

Para otros autores, tales como Schott ${ }^{20}$, la lentitud de las negociaciones obedece a dos razones. Por un lado, las tácticas de negociación y las propuestas de países determinados o coaliciones regionales y por el otro, el hecho de que las estipulaciones que contemplan los mandatos ministeriales son deficientes.

Algunos han señalado que se trata de un problema de expectativas, confianza e información, así como de evidente falta de liderazgo en el proceso. Por otra parte, cabe recordar que la práctica para negociar también indica que para alcanzar resultados que influyan positivamente en los actores hay que exagerar las diferencias.

19 El 26 de junio de 2003, los ministros de Agricultura de la UE aprobaron una reforma en profundidad de la Política Agricola Común (PAC), <http:/ec.curopa.cu/agriculture/ capreform>.

20 Schott, Jeffrey, «Finalización de la ronda Doha: qué se debe hacer y quiénes deben hacerlo", Instituto de Economia Intcrnacional, Washington, septicmbre de 2006. 
Finalmente, también contribuyó a la suspensión la propia naturaleza de las negociaciones multilaterales entre países tan diferentes y el elevado nivel de expectativas de esta Ronda, que se programó para un periodo muy corto.

\section{LAS CONSECUENCIAS DE UN POSIBLE FRACASO DE LAS NEGOCIACIONES Y EL REGIONALISMO}

E] fracaso de las negociaciones fracasaran podría dar lugar a un proceso lento de debilitamiento del sistema de la Organización Mundial de Comercio. En efecto, la pérdida de confianza en la OMC como foro negociador provocaría un progresivo olvido del sistema. "Y entonces el costo lo pagaría la OMC, que podría deslizarse gradualmente hacia lo peor que le pudiera ocurrir. Esto es, su inclinación hacia una gradual pero creciente irrelevancia. ${ }^{21}$ Si esto ocurriera, los más perjudicados serían los países en desarrollo y menos adelantados, puesto que son ellos los «principales beneficiarios del sólido sistema sustentado en normas multilaterales ${ }^{22}$.

El posible fracaso de la Ronda no solo significaría perder una oportunidad única en el proceso de liberalización comercial, sino que pondría en serio entredicho la credibilidad del sistema multilateral en su conjunto. La OMC no es solo un foro de negociaciones comerciales, sino también un sistema de reglas que rigen el comercio internacional. Son estas reglas y disciplinas las que más benefician a los países en desarrollo, que necesitan de una institución que garantice la protección de sus derechos comerciales.

El mecanismo de solución de controversias de la OMC ha logrado igualar a economías pequeñas y desarrolladas, $y$ ha permitido defender los intereses de los miembros frente a posibles medidas discriminatorias o proteccionistas que podrían aplicar terceros países. El cuestionamiento de estos principios y la pérdida de confianza en el sistema de solución de controversias socavarían lo que muchos consideran un bien público internacional. ${ }^{23}$ Asimismo, es muy discutible cuán sostenible sea la práctica de litigar en un foro en que no se negocia. Es necesario contar con reglas claras y con un sistema de solución de controversias eficaz que atienda las necesidades de los países en desarrollo.

Otro aspecto que hay que tener presente en caso de tropiezo de las negociaciones es el hecho de que coexistan el sistema multilateral de comercio y muchos subsistemas basados en acuerdos preferenciales. La firma de estos acuerdos ha permitido avanzar en el proceso de liberalización comercial. Se calcula que en 2010 en el mundo habrá

21 Peña, Felix, «Interrogantes Sobre El Futuro: Las negociaciones comerciales tras las elecciones en Brasil y en los Estados Unidos", 2006.

22 Schott, Jeffrey, op. cit., p. 21.

23 Kindleberger, "Notas de la CEPAL», CEPAL, julio del 2006. 
más de 400 acuerdos de este tipo ${ }^{24}$. A pesar de la proliferación de acuerdos regionales, bilaterales y plurilaterales, la OMC parece seguir siendo el mejor camino para liberalizar el comercio y fortalecer algunas áreas específicas. Pese a que Chile es una de las economías que ha suscrito el mayor número de acuerdos preferenciales en el mundo, apoya un sistema comercial multilateral de carácter universal. «El sistema multilateral del comercio no es perfecto, sin embargo, es el único capaz de generar reglas de validez universal para garantizar un mejor acceso a los mercados de los países ${ }^{25}$. Si bien los acuerdos comerciales preferenciales pueden traer consigo importantes beneficios, también tienen algunos inconvenientes, en particular para los países en desarrollo. Ante la posibilidad de que fracasen las negociaciones en el ámbito multilateral, es preciso tenerlo presente.

En primer lugar, el poder negociador de los países en desarrollo en el ámbito bilateral es muy inferior al que pueden alcanzar en el escenario multilateral. Al negociar acuerdos bilaterales del tipo norte-sur, los países en desarrollo suelen verse obligados a aceptar condiciones que no les son favorables para lograr la apertura de los mercados.

En segundo lugar, la firma de diferentes acuerdos comerciales preferen- ciales trae consigo diversas reglas de origen, niveles tarifarios y procedimientos aduaneros. Esto acarrea un alto costo de monitoreo a nivel de aduanas ya que para poder aplicar la normativa vigente hay que identificar y clasificar los distintos envíos según su procedencia. Los costos de administración y de ejecución de los diversos tratados es un tema de especial cuidado, en particular cuando hay servicios de aduana que no disponen del personal y la tecnología necesarios para hacer frente a estos requerimientos. A nivel empresarial, las normas divergentes y en muchos casos poco claras debilitan las posibilidades de negocios, porque desalientan y confunden a los empresarios, perdiéndose así el ingreso a nuevos mercados. La creación de una normativa multilateral en estas áreas simplifica los trámites aduaneros, facilitando el tránsito de las mercancías y aclarando la imagen para los negocios internacionales, al enfrentar reglas claras universales.

La proliferación de acuerdos preferenciales, "que se está desarrollando en forma muy perjudicial para el sistema de la $\mathrm{OMC}^{26}$, plantea a esta un gran desafio: lograr mejorar la sinergia entre dichos acuerdos y el sistema multilateral de comercio. En los últimos años la OMC ha visto crecer el regionalismo y debe afinar su convivencia con él a fin de minimizar sus riesgos. Los

24 Ocampo, Fernando, «Reflexiones sobre los desafíos que plantea la liberalización del comercion, Mesa Redonda sobre el Futuro de Doha, en el Instituto de Estudios Internacionales, 2006.

2s Rosas, Maria Cristina, La OMC y la Ronda de Doha, UNAM, 2003.

26 Schott, Jeffrey, op. cit., p. 22. 
acuerdos comerciales preferenciales pueden ser un camino que abra las posibilidades de un sistema multilateral más fuerte. Ello se lograra si a medida que los países abren sus economías a nivel bilateral o regional se establecen las condiciones necesarias para que puedan multilateralizarse los beneficios. Por el contrario, si los países pretenden mantener sus preferencias arancelarias con determinados socios comerciales, ante un acuerdo multilateral ellas se verían debilitadas. Así, los acuerdos comerciales preferenciales podrian significar un estancamiento, si no un retroceso, en el proceso de liberalización comercial general a que se aspira bajo la OMC.

Al respecto, en el marco de las negociaciones se han logrado avances en materia de transparencia, ya que hay consenso en que los informes son elaborados por la Secretaría y no por los paises. En lo que respecta a decisiones, hay consenso en que la transparencia es el úmico mecanismo útil parn alcanzar una verdadera liberalización.

Los acuerdos comerciales firmados en los últimos años han sido principalmente entre países en desarrollo (SurSur), o bien entre un país desarrollado $y$ otro en desarrollo (Norte-Sur). La paralización de las negociaciones podría acelerar las negociaciones entre países desarrollados para la firma de tratados. de libre comercio de tipo Norte-Norte. "Los acuerdos de libre comercio llamados "Norte-Norte" fueron objeto de estudios y rechazados por su efecto potencialmente negativo en el sistema multilateral de comercio.» 27 Estos acuerdos podrian representar una seria amenaza para el comercio de los países en desarrollo.

Las sucesivas rondas de negociaciones en el marco del GATT sirvieron de freno a los intereses proteccionistas de algunos miembros. A su vez, nuevas barreras que habían creaclo los países para limitar el comercio han sido incluidas en el campo de acción de la OMC a fin de regular las präcticas que pudieran resultar desleales para el comercio internacional. Si fracasara Doha, se rompería este freno explícito e implícito al aumento del proteccionismo. Sin él, los países tendrán vía libre para aumentar la protección, en especial utilizando aquellas prácticas que no acatan las disciplinas de la OMC.

El posible fracaso de la Ronda de Doha obliga a contemplar otros dos costos importantes. En primer lugar, los impactos adversos que dicho fracaso pudiera tener en los mercados financieros, principalmente por las proyecciones de un nuevo proteccionismo y su reflejo en la caída de los precios de los activos. En segundo lugar los países en desarrollo perderían la posibilidad de recurrir a las negociaciones económicas multilaterales como anzuelo para realizar sus reformas económicas internas. La desaparición de este pretexto los obligaría a enfrentar por su cuenta los desafios de la globalización, en particu-

27 Schott, Jeffrey, op. cit., p. 23. 
lar el crecimiento de actores como China y la India.

Si la Ronda terminara por fracasar, no solo enfrentaríamos lo antes señalado sino que se perdcría todo lo acordado hasta la fecha. Hay que recordar que el Programa de Doha para el Desarrollo tiene un alto grado de ambición: por una parte las profundas reformas que se pretende introducir y por la otra, la diversidad de temas que se están abordando en las distintas mesas de negociación. Al interior de estas mesas, muchos de estos temas ya han sido objeto de acuerdos que impactarían y beneficiarían de manera directa a los países en desarrollo, y perderlos involucraría un enorme costo. Temas clave, incluidos no solo los subsidios agricolas sino también el uso de mecanismos antidumping, solo pueden resolverse multilateralmente. Por esta razón, las disposiciones relativas a este tema y la posibilidad de transparentar los acuerdos comerciales regionales mediante la elaboración de un informe por la Secretaría y no por los mismos Estados involucrados generará un clima de mayor estabilidad en el comercio mundial.

Los avances logrados en la mesa de negociaciones agrícolas son importantes, en particular respecto de la Ronda Uruguay. Entre ellos cabe destacar la eliminación de los subsidios a las exportaciones agrícolas, propuesta por la Unión Europea para el año 2013. Si dicha eliminación no se multilateralizara en el marco de las negociaciones de la OMC, dificilmente se respetará en el largo plazo, ya que no existirá un instrumento jurídico intemacional que prohíba volver a utilizar dichos subsidios. Por orra parte, $y$ a diferencia de lo que ocurrió en las rondas anteriores, la Ronda de Doha ha iniciado las negociaciones en torno a los subsidios pesqueros. Para los países en desarroHlo costeros, este es un tema fundamental para preservar sus recursos pesqueros, en especial las especies altamente migratorias o tranzonales, ya que las flotas subsidiadas, en particular las europeas, han depredado los recursos que poseen frente a sus costas.

Si no se retoman las negociaciones se perderá todo lo negociado, lo cual implicará un enorme costo para los países en desarrollo. Por sus especiales características estos temas no serán negociados en foros alternativos al de la OMC. Por esta razón, muchos países han propuesto la alternativa de concretar una Ronda Light, que capitalice lo ya logrado, a fin de concretar estos avances de modo que no dependan de lo que aún falta por negociar.

\section{LA REGIÓN Y EL SIS'TEMA multilateral de comercio}

La apertura comercial se ha definido como una de las variables que inciden positivamente en el crecimiento económico a largo plazo. Sin embargo no parece haber evidencia definitiva del impacto de la apertura para el desarrollo. En América Latina la política comercial sigue siendo un tema controvertido debido en parte al desempeño 
disímil de la actividad económica en la región. No obstante, la tendencia a la liberalización y la evidencia de que la solución no es el volver al proteccionismo indican que la región debe dar prioridad a la reanudación de la Ronda de Doha.

De acuerdo con estimaciones de la $\mathrm{OCDE}^{28}$, la plena liberalización de bienes industriales y agrícolas permitiría lograr 100 mil millones de dólares en utilidades, mientras que los beneficios de la liberalización del comercio de servicios se elevarían aproximadamente a $500 \mathrm{mil}$ millones de dólares. Un acuerdo de Doha para facilitar el comercio que suprimiera barreras de procedimiento podría contribuir como mínimo con otros 100 millones de dólares, dos tercios de los cuales corresponderían a los países en desarrollo. Un estudio reciente de las Naciones Unidas ${ }^{29}$ señala que si se eliminaran todas las barreras comerciales, los países en desarrollo podrían obtener ganancias por $130 \mathrm{mil}$ millones de dólares al año, lo que hace parecer que los $50 \mathrm{mil}$ millones de dólares anuales de asistencia que se requieren para alcanzar en 2015 los Objetivos de Desarrollo del Milenio parezcan una suma pequeña.

Para América Latina, además de perder ingresos, el fracaso de la Ronda de Doha acarrea otros riesgos, por ejemplo, que los países del primer mundo sigan imponiendo barreras arancelarias y no arancelarias mediante acciones arbitrarias tales como el anti-dumping, los enormes subsidios que distorsionan los precios y el proteccionismo a nivel mundial.

Asimismo, considerando que las economías de la región disponen de escasos recursos humanos, por mucho que algunos países cuentan con acuerdos preferenciales bilaterales o regionales, la reanudación de las negociaciones debe ser prioritaria para los gobiernos. Para Bhagwhati ${ }^{30}$ los esfuerzos de los países en desarrollo por negociar acuerdos preferenciales reducen sus posibilidades de obtener beneficios más importantes en el ámbito multilateral. Las negociaciones tienen la ventaja de que se negocia simultáneamente con los 150 países por el precio de una sola negociación.

Aunque la liberalización comercial no es la solución, ofrece oportunidades y economías como las nuestras que tienen escaso peso en el comercio mundial deben aprovecharlas en un entorno multilateral. La región debería cohesionarse y plantearse objetivos claves, como estar dispuestos a asumir ciertos costos frente a la reanudación de las negociaciones de la Ronda de Doha. De lo contrario, cada país debe tener

28 Gurría, Ángel, Secretario General de la Organización para la Cooperación y el Desarrollo Económicos (OCDE), "Doha: the low hanging fruit", OECD Observer <http:/l www.occdobserver.org $>$, agosto del 2007.

29 Naciones Unidas, "Cambiar la pobreza", <http://www.un.org>, 2006.

30 Stern, Robert, "Overview: Perspectives on the WTO Doha Development Agenda Multilateral Trade Negotiations", Global Economy Joumal, Vol. 5, número 4, 2005. 
claras sus prioridades y buscar las alianzas correspondientes, pese a que siempre es mejor la vida en un vecindario próspero y armonioso.

Para algunos, con la suspensión de la Ronda, en América Latina el debate comercial parece apuntar a dos extremos: el incremento de sus vínculos con China y Asia-Pacífico o darle prioridad a sus vecinos. Pese a la reducción de las distancias geográficas que ha traído consigo la globalización y a la disminución de los costos de transporte, los países tienen en sus vecinos un factor muy importante de expansión económica y comercial ${ }^{32}$.

En la presente sección se dan a conocer las posiciones que han sostenido y deberian sostener los países de la región ante la posible reanudación de las negociaciones, así como algunos de los riesgos que acarrearía el posible fracaso de la Ronda. Es evidente que la situación no afecta de igual manera a los distintos actores de la región, si bien debido a las características de sus economías y a las diferencias en la definición de su política comercial y las prioridades que tiene cada país, ello se revisa en la segunda parte.

En materia agrícola, la región tropieza diariamente con dificultades para acceder a los mercados de Estados Unidos y Europa y debe tratar de superarlas. Los países deben sostener su posición respecto de los apoyos internos y su disminución, asî como la necesidad de mayor certeza respecto de sus efectos distorsionantes. Aunque cualquier ayuda interna que se mantenga puede concentrarse en un número reducido de productos, es posible que estos sean los de mayor interés para los países de la región. Asimismo, negociar la eliminación de los subsidios es prioritario, ya que nuestros países carecen de ingresos suficientes para otorgarlos.

Los paisses de la región deberían buscar mejores ofertas de acceso a mercados, sin excesivas demandas de reciprocidad que puedan eliminar los beneficios provenientes de dicho acceso. La rebaja generalizada de los aranceles no agropecuarios que se exige a los países en desarrollo podría eliminar un mecanismo que puede ser esencial para su desarrollo económico. Este mecanismo es el mismo que los países industrializados utilizaron en sus propios procesos de industrialización. Por ejemplo ${ }^{32}$, entre 1820 y 1931 los Estados Unidos aplicaron a los bienes industriales una tarifa promedio de $40 \%$ a $50 \%$. Asimismo, la región debe negociar la eliminación de las crestas arancelarias y el escalonamiento, a fin de que las economías en desarrollo no se orienten a consolidar una especialización en productos manufacturados de mayor valor agregado, propia de los países del Norte, relegando a los del Sur, excepto los más avanzados, a ser proveedores

31 Reuters, "Análisis 2007: con Doha y TLC en peligro, América Latina necesita Asia», $<$ http/l:www.reuters.com>, 16 diciembre de 2006.

32 Correa, Carlos, “La Ronda de Doha: expectativas y frustraciones de los países en desarrollo", CEIDEI, noviembre de 2006. 
de productos agrícolas de menor valor agregado.

En materia de servicios, un estudio reciente demostró que si los países industrializados permitieran a los países en desarrollo un acceso equivalente al $3 \%$ de su fuerza laboral, sus ganancias superarían los 150 mil millones de dólares, esto es, más de lo que obtendrían si se liberalizara el comercio de bienes ${ }^{33}$. Los países de la región deben analizar el impacto de sus compromisos, y contar con disposiciones de trato especial y diferenciado, así como presionar por obtener mayor liberalización en el Modo 4.

El desarrollo de la facilitación del comercio y la integración regional se vinculan estrechamente con la eficiencia de los servicios públicos y la competitividad de las empresas en apoyo de la actividad exportadora ${ }^{34}$. Al respecto, los países del continente americano debemos estar conscientes del desafío competitivo que enfrentamos por parte de Asia. Asimismo, se ha sostenido que los avances en la facilitación del comercio podrían permitir a América Latina y el Caribe potenciar una ventaja clave que es la proximidad de la región a Estados Unidos, Canadá y Europa y la mayor rapidez para llegar al mercado que ello puede significar. Un estudio del Banco Mundial determinó que un tercio de los beneficios de las negociaciones de la Agenda de Desarrollo de Doha podrían provenir de la facilitación del comercio.
Los países deben examinar seriamente el tema del trato especial y diferenciado ya que hasta ahora no se han aprovechado cabalmente las mejores condiciones comerciales de los países en desarrollo y en particular de los países menos adelantados para mejorar el desempeño exportador. Como se reconoció en la Cumbre de las Naciones Unidas, bien orientado, el programa de ayuda para el comercio «Aid for Trade» es quizá lo más importante.

En opinión de la CEPAL el efecto del ciclo económico mundial, que depende cada vez más del vínculo entre Estados Unidos y China, es más favorable para América del Sur y en menor medida para México. Sin duda Asia constituye para la región un competidor agresivo.

En la región, Chile y México han seguido caminos similares. Ambos han sido considerados los alumnos aplicados de la región en materia de liberalización comercial. En estas economías que tienen cubierta la mayor parte de su comercio con acuerdos de libre comercio, los efectos a corto plazo de la suspensión de la Ronda de Doha no son tan peceptibles.

Sin embargo, aún hay aspectos que es más difícil resolver bilateralmente, tales como la persistencia de los subsidios a las exportaciones agrícolas y el hecho de que estos no estén cubiertos por acuerdos de libre comercio con todos los países. Si la Ronda fracasara, también fracasará el intento de mejo-

33 Mattoo, Aditya, op. cit.

34 CepAL, "Boletín, la facilitación del comercio y la integración centroamericana: modernizaciön de aduanas", $\mathrm{N}^{\circ} 222$, febrero de 2005. 
rar las normas para evitar que se cometan abusos con las medidas antidumping. Por otra parte, se han hecho esfuerzos por limitar el empleo de subvenciones en el área pesquera, que llevan a que se mantengan las flotas y se induzca a una sobreexplotación.

A fin de reducir los efectos perjudiciales que puede tener este tipo de subsidios para el comercio, el desarrollo y el medio ambiente, Chile ha encabezado la solicitud de que en principio se prohíban los subsidios a la industria pesquera y de que posteriormente se negocien algunas excepciones. Se trata de un aspecto fundamental del marco multilateral que impacta también a los países centroamericanos y que sería imposible resolver en el plano bilateral.

México deberá sortear la aparición de China en el escenario, y es sin duda en el plano multilateral donde debe definir su estrategia. Al parecer la participación en Medio Oriente es un nuevo objetivo para Chile y México, pero para alcanzarlo deberán definir una nueva estrategia de política exterior.

Por otro lado, para aprovechar las ventajas de la apertura todavía está pendiente la cuestión de la movilidad de las personas, lo que México no ha podido lograr mediante sus acuerdos de libre comercio, en especial en el marco del TLCAN.

El fracaso de Doha podría dificultar el reto de diversificación en materia exportadora que deben realizar tanto México, particularmente con respecto de sus mercados de destino, como Chile, en cuanto a sus productos. Tanto el petróleo, pese a que ya no es la primera fuente de exportaciones, como el cobre, son fundamentales para ambas economías. Los precios de los productos básicos se han vuelto más inestables y la mayoría de ellos ha aumentado, y se espera que en 2007 se moderen. Aunque esto puede lograrse mediante otras iniciativas de liberalización, hasta ahora no ha sido el caso.

La situación y la posición de Chile y Costa Rica han sido coincidentes. En el ámbito agrícola, Costa Rica ha abogado por una reducción ambiciosa de los aranceles que aplican Japón, la UE y la India, y ha apoyado al Grupo Cairns para se reduzcan las ayudas internas. Para Oscar Arias, los países en vías de desarrollo no tienen otra opción que la integración con la economía mundial.

Debido a su relación de dependencia con los Estados Unidos, el caso del resto de los países centroamericanos es en muchos aspectos similar al de México. Con un incipiente CAFTA, y con economías principalmente exportadoras de productos agrícolas, se estima que la estrategia óptima es desmantelar las barreras a nivel multilateral. Nicaragua, Guatemala, El Salvador y Honduras han planteado la importancia de lograr resultados concretos y efectivos en el Programa de Trabajo sobre Economías Pequeñas y Vulnerables.

Además de que las economías centroamericanas tienen una profunda tradición agrícola, para ellas el futuro de la Ronda se vincula estrechamente con la negociación del banano. Para estos países, este es un tema sensible, y ven 
con preocupación el logro del compromiso de la Ronda Doha de alcanzar la mayor liberalización de productos agropecuarios, en especial de los productos tropicales.

Panamá se esta convirtiendo cada vez más en centro de distribución de productos hacia toda Centroamérica y en un centro muy sofisticado de provisión de servicios no solo financieros sino también de transporte, por lo cual le interesa mejorar el acceso a los productos tropicales, los productos del mar, los servicios financieros, los servicios marítimos y el turismo.

Si bien los países de Centroamérica y el Caribe se han beneficiado con el incremento de las exportaciones y del turismo, que les ha permitido sostener la tasa de crecimiento, la liberalización en materia de servicios permitiria que se vieran notablemente favorecidos.

La suspensión de las negociaciones ha repercutido de diversas maneras en el Mercosur. En primer lugar debemos recordar que Brasil es uno de los países más importantes del G-20, por lo que la reanudación de las negociaciones depende en gran medida de que logre liderar a los países en desarrollo al respecto. De todos modos, una de las primeras medidas que es necesario adoptar al interior del Mercosur es tratar de relanzar las negociaciones bilaterales orientadas a lograr un acuerdo de asociación con la Unión Europea, que incluiría un importante capítulo comercial. Por otra parte, Paraguay estaría explorando caminos que podrían conducir a la firma de un tratado de libre comercio con los Estados Unidos, lo que no solo podría plantear un problema de incompatibilidad con la OMC, sino también con la propia unión aduanera que pretenden crear los países del Mercosur.

Los países andinos han recibido de distinta manera la suspensión de las negociaciones de la Ronda de Doha. Los recientes cambios políticos ocurridos en la región no permiten hablar en términos generales sobre la realidad de los cinco países que otrora formaban parte de la Comunidad Andina. Entre los principales factores que han influido en ellos cabe mencionar la elección y posteriormente la reelección de Hugo Chávez a la presidencia de Venezuela y su manejo de la política exterior. Ella llevó al retiro del país de la Comunidad Andina y a su ingreso como miembro pleno al Mercosur, luego de que Perú y Colombia decidieron negociar bilateralmente tratados de libre comercio con los Estados Unidos, debilitando el ya frágil proceso de integración andino. Así, al interior de lo que comúnmente denominábamos países andinos pueden distinguirse dos bloques: por una parte el bloque liderado por Venezuela, junto con Bolivia y Ecuador, y por la otra, Perú y Colombia.

Las negociaciones en la OMC no han sido una prioridad en la agenda de política comercial de Venezuela. Sus principales apuestas se han generado al interior de América Latina, en especial con la creación del ALBA (Alternativa Bolivariana para la América) de la cual también forman parte Bolivia, Cuba y 
Nicaragua. A pesar de lo anterior, Venezuela está presente en diversos grupos del foro multilateral, destacándose el NAMA-11, desde el cual apoya abiertamente la reanudación de las negociaciones de la Ronda. Por otra parte, el fracaso de la Ronda reforzaría el papel del ALBA en la región, y de esta manera Chávez podría adquirir mayor poder en América Latina, y perfilarse como un claro líder en la región.

Para Bolivia, la Ronda de Doha tiene especial relevancia por la inclusión de los temas de Singapur, en particular las negociaciones sobre facilitación del comercio. En su calidad de país sin litoral, esta negociación adquiere mayor importancia ya que la mayoría de los productos bolivianos están sujetos al transito por terceros países. Junto con lo anterior, y debido a su condición de país económicamente menos adelantado, Bolivia ha tenido mucho interés en que se contemple un trato especial y el suministro de asistencia técnica para ellos. La suspensión de la Ronda paralizó el trabajo en las distintas mesas de negociación, incluidas las de facilitación y ello es motivo de preocupación para las autoridades bolivianas. Ante un fracaso definitivo de las negociaciones, las alternativas del país serían profundizar las relaciones comerciales en el marco del ALBA y negociar bilateralmente con los países de tránsito de sus productos, en particular Chile, para así poder proyectarse hacia el Pacífico.

La participación de Ecuador en el sistema multilateral de comercio está marcada por el régimen de importación impuesto por la Unión Europea a su producto estrella, el banano. Ecuador ha sido parte en diversos paneles contra la UE por este caso, y en la actual Ronda su principal preocupación ha sido lograr que se logre modificar este régimen, que afecta a sus exportaciones. De ahí que preste especial atención al área agrícola, en la cual participa activamente pese a que no se ha incorporado a ninguna de las alianzas existentes. El fracaso de la Ronda mantendría inalteradas las políticas de la UE, lo que para Ecuador significaría un enorme problema. La reciente llegada al poder de Rafael Correa, cercano a Hugo Chávez, podría llevar a Ecuador a unirse al ALBA, $y$ buscar en este grupo una alternativa al posible fracaso de Doha.

Perú y Colombia han modificado su estrategia de política comercial, antes muy ligada al desarrollo de la Comunidad Andina de Naciones, y la han orientado hacia una política más autónoma. Producto de ello, se han embarcado en una profunda estrategia de negociaciones comerciales bilaterales que persigue la liberalización de sus exportaciones a sus principales socios comerciales. Esta estrategia confronta una situación directamente relacionada con los cambios políticos que se viven al interior del Capitolio norteamericano. Ambos países han negociado un tratado de libre comercio con los Estados Unidos y el retorno al poder de los demócratas en ambas cámaras del parlamento los perjudica seriamente, ya que de acuerdo con las primeras proyecciones se da por 
hecho que su nueva composición impedirá que se ratifiquen los TLC.

Enfrascarse en esta estrategia de liberalización bilateral no quiere decir que las negociaciones en el marco de la OMC carezcan de importancia. Hay temas que por su complejidad solo pueden ser resueltos a nivel multilateral. Para Colombia, los subsidios que otorga Estados Unidos a su agricultura distorsionan en gran medida su comercio bilateral con este país, que resulta ser su principal socio comercial. De ahí que sea fundamental lograr un acuerdo sobre el tema en el marco de Doha y el fracaso de la Ronda impediría eliminar estos subsidios, perjudicando gravemente a su agricultura y con ello, los planes de reemplazo del cultivo de coca.

Para Perú, la importancia fundamental de la OMC radica en su rol sistémico a nivel global. «Es importante la participación del Perú en las negociaciones de la OMC porque esta significa estabilidad en las reglas de juego, integrarnos cada vez más al mundo mediante el comercio y contar con la posibilidad de utilizar el Mecanismo de Solución de Diferencias" ${ }^{35}$. De ahí que un fracaso en las negociaciones de Doha no influiría mayormente en la liberalización de las exportaciones peruanas, sino más bien en la merma de las posibilidades de que exista un foro multilateral que dicte las reglas del juego para todos los actores del comercio internacional.

Por una parte, el fracaso definitivo de las negociaciones llevaría a Colombia y Perú a profundizar su política de acuerdos preferenciales y, como consecuencia de su natural proyección al $\mathrm{Pa}-$ cífico, a asumir un nuevo rol en las relaciones entre América Latina y el Asia. Es muy probable que en los próximos años se firme un creciente número de acuerdos entre algunos de estos países y los países de la cuenca occidental del Pacífico. El presente año Perú será anfitrión de una nueva reunión del APEC y Colombia ha mostrado interés en participar de esta iniciativa regional.

La situación de los países del Caribe en torno a la Ronda de Doha para el Desarrollo no puede compararse con la del resto de la región. Las relaciones comerciales del Caribe están fuertemente determinadas por su dependencia de las preferencias que le otorgan los programas especiales de la Unión Europea y Estados Unidos, con lo cual tienen un acceso libre de aranceles a los principales mercados de los países desarrollados. Debido a esta particular situación, las prioridades de los países del Caribe en las negociaciones del programa de Doha se han centrado en las áreas de creación de capacidad, de trato especial y diferenciado a las pequeñas economías, de acuerdo en las modalidades para llegar al consenso y el suministro de asistencia técnica y financiera.

Como podemos notar, los «grandes temas" que llevaron a la suspensión de la Ronda, como el acceso a los merca-

3s Angell, Allan, asesor del viceministerio de Integración y Negociaciones Comerciales Internacionales, <http://www.mincetur.gob.pe>. 
dos agrícolas, no se cuentan entre las «prioridades» del Caribe. De todas formas, los países caribeños no son indiferentes a lo que suceda en estas áreas de negociación. Un avance significativo de ellas podría perjudicar gravemente a sus economías. Por ejemplo, la propuesta costarricense de excluir los productos tropicales de las listas de productos sensibles de los países desarrollados es vista con preocupación por el Caribe, ya que esto socavaría las preferencias de que disfruta actualmente.

La reciente reanudación de los trabajos técnicos en Ginebra ha sido muy bien recibida por los negociadores del Caribe. La falta de recursos humanos para hacer frente a muchas negociaciones es un problema general de la región y el Caribe no es excepción. Enfrentar una negociación multilateral es política y económicamente preferible a enfrentar muchas negociaciones bilaterales. Además, por su tamaño económico-comercial, es importante considerar que las economías del Caribe no son socios comerciales atractivos, y en el caso de una negociación Norte-Sur tienen escaso poder de negociación, mientras que en el foro multilateral de la OMC cuentan con un poder equiparable al de cualquier país desarrollado, puesto que tienen la posibilidad de realizar alianzas con otros países y también de oponerse al consenso.

\section{Consideraciones finales}

Las repercusiones de la suspensión de las negociaciones y el futuro de la Ronda de Doha son temas que por su relevancia y su difusión revelan claramente el interés por la liberalización comercial y la importancia de que exista un foro multilateral al respecto. Esto se puede apreciar particularmente por la mayor participación de los países en desarrollo en estos procesos.

Al parecer se ha sobredimensionado la importancia de la suspensión y pese a que se han visto fuertes apoyos politicos, los cambios reales no son muy evidentes. A pesar de que otras Rondas del GATT y la OMC han tenido tropiezos antes de llegar a una conclusión satisfactoria, el fracaso de Doha sería la primera vez que no se obtendrían resultados. Se ha indicado que la principal dificultad radica en lo difícil que es sacar dinero para todos del bolsillo de unos pocos. La pregunta es siempre si hay voluntad política para avanzar en estos temas.

El ambiente político mundial ha crecido en complejidad y ello ha generado nuevos desafíos para la finalización de las negociaciones.

En la Unión Europea existe la impresión de que difícilmente podrá lograrse que se amplíe la oferta en materia de acceso a los mercados de los productos agrícolas antes de las elecciones presidenciales en Francia y de que se hayan resuelto los problemas relacionados con las nuevas adhesiones.

El otro gran actor, Estados Unidos, 
atraviesa por problemas de carácter político y estratégico que le son más relevantes y cruciales que los aspectos económicos y comerciales.Sin embargo, estudios sobre el comportamiento político de los nuevos representantes y senadores que han llegado al Capitolio no confirman los primeros temores de que no se renueve la TPA ${ }^{36}$. En general, los nuevos congresistas son reacios a la firma de acuerdos preferenciales con pequeñas economías en desarrollo. Al respecto, las palabras del presidente del Partido Demócrata, Howard Dean, son categóricas: «No creo que veamos nuevos acuerdos comerciales ${ }^{37}$. Pese a lo anterior, los estudios coinciden en que pocos criticaron las negociaciones en el ámbito multilateral. Si las negociaciones de la Ronda de Doha fructificaran y el acuerdo resultante revitalizara el crecimiento de la economía estadounidense, promoviera el alivio de la pobreza en el mundo en desarrollo y reforzara la cooperación global, estaría sin lugar a dudas dentro de los intereses norteamericanos. «De esta forma, el Ejecutivo podría solicitar la extensión de la TPA únicamente para las negociaciones de Doha " ${ }^{38}$.

Por un lado, al parecer la postura reguladora de la Unión Europea se basa en su modelo de sociedad del bienestar, mientras que los Estados Unidos buscan desregular los mercados externos basados en su depredador modelo de mercado.

La región, en conjunto con los demás países en desarrollo, debe exigir coherencia en el discurso y en la política de los países desarrollados. Las alianzas de geometría variable ya no responden a criterios de regiones geográficas, sino a intereses comerciales coincidentes. A pesar de que la llamada «sopa de letras» ha sólido provocar en ocasiones el debilitamiento de las posiciones negociadoras.

Sin embargo, para que avancen las negociaciones es importante formar coaliciones que den legitimidad y coordinen las posiciones de los países, por lo cual la región debe contemplar la posibilidad de adoptar una posición común, o al menos coordinada. Aunque está claro que el discurso político de los países de América Latina y el Caribe parece ser cada vez más divergente, se podría hacer coincidir sus prioridades en materias comerciales a fin de que en las mesas de negociación se logre un propuesta que no represente necesariamente el mismo discurso político.

América Latina se encuentra en una encrucijada. Puede consolidar sus logros de integración económica o puede retroceder debido a la retórica de algunos países que culpan de todo a la globalización. Es preciso que a largo

36 Evannett, S. y Meicr, M., "The U.S. Congressional Election in 2006: What implications for U.S. Trade Policy?, Universidad de St. Gallen, 2006.

37 "Los Demócratas en el Congreso, posibles cambios en el comercio internacional», Puenttes, octubre-diciembre de 2006.

Ibid. 
plazo la región dé muestras de coherencia, consistencia y consenso a fin de realizar reformas que mejoren su competitividad.

Como se señaló en la sección anterior; a pesar de las diferencias, existen mayores espacios de convergencia. Hay temas claves, incluidos no solo los subsidios agrícolas o pesqueros sino también el uso de mecanismos antidumping, que solo pueden resolverse multilateralmente.

Para que sobreviva la Ronda de Doha el desafío consiste ahora en generar la voluntad política necesaria para avanzar y moderar las expectativas. En opinión de Alejandro Jara. "De otro modo, las negociaciones no van a ninguna parte» ${ }^{39}$. El trabajo técnico está hecho; lo que se necesita ahora es decisión política y liderazgo departe de las principales potencias del mundo.

Del análisis de los riesgos de un fracaso se deduce que los estudios parecen coincidir en que los costos serán sin duda mayores para los países en desarrollo. Si los países de la región no aumentan sus exportaciones de bienes y servicios, terminarán exportando cada vez más personas ${ }^{40}$.

En América Latina, el panorama de la integración se ha transformado más bien en un proceso de desintegración regional, como lo revela el relativo impasse en que se encuentran el Mercosur y la Comunidad Andina, la suspensión de las negociaciones del ALCA, la creación del ALBA y las propuestas de integración que contienen claras exclusiones. En este escenario, la única subregión en que se mantiene el proceso de integración es Centroamérica.

El hecho de que los países en desarrollo, en particular Brasil, hayan abandonado el enfoque reactivo y adoptado un criterio activo en las negociaciones es favorable. Según puede a preciarse en numerosas propuestas y estudios los delegados de los países de la región han tenido mayor tiempo para analizar su posición negociadora.

Aunque la suspensión de la Ronda podría derivar en un fracaso, podría generar muchas otras alternativas a la $\mathrm{OMC}_{\text {, }}$ tales como un foro de negociaciones plurilaterales o una solución intermedia y el inicio de una nueva Ronda.

La evolución de la economía de América Latina y el Caribe en 2007 se observa con cautela, entre otras razones por la incertidumbre acerca del curso que ha de seguir la economía internacional. Asimismo, la liberalización comercial es una política más del desarrollo la región que exige reformas tales como realizar inversiones en desarrollo humano y educación, desarrollar la institucionalidad, etc.

Para los expertos, Doha no tendrá éxito mientras no se generen los cam-

39 Jara, Alejandro, "La liberalización del comercio en la Ronda Doha de la OMC», <http:// www.amcham.cl>, 7 de septicmbre de 2006.

to Arias, Oscar, "Apertura comercial y desarrollo social en América Latina", Conferencia Magistral, CEPAL, Chile, 6 de noviembre de 2006. 
bios necesarios para crear una nueva base de negociación que permita llevarla a feliz término.

Por de pronto, el 7 de febrero de 2007, Pascal Lamy anunció al Consejo General que se habían reanudado las negociaciones en todas las esferas, pero ello no significa una conclusión exitosa de esta Ronda. En efecto, la posibilidad de un fracaso de la Agenda Doha se mantendrá la- tente mientras la posición de los miembros de la OMC no dé muestras de la flexibilidad necesaria al momento de negociar. Así lo revela el Salzburg Retreat del 16 de febrero del presente año, oportunidad en que los principales expertos y partes involucrados en el tema se reunieron a analizar, en el contexto global, los posibles beneficios y costos de un fracaso en las negociaciones. 